\title{
Effectiveness of Motivationally Adaptive Computer-Assisted Instruction on the Dynamic Aspects of Motivation
}

\author{
Sang H. Song \\ John M. Keller
}

The purpose of this study was to examine the effects of a prototype of motivationally-adaptive computer-assisted instruction (CAI). The foundation for motivational theory and design was provided by the ARCS model (an acronym formed from attention, relevance, confidence, and satisfaction). This model provides a definition of motivation, a motivational design process, and recommendations for motivational strategies. Three treatment conditions were considered: (a) motivationally adaptive CAI, (b) motivationally saturated CAI, and (c) motivationally minimized CAI. Dependent variables were effectiveness, perceived motivation (both overall motivation and each of $A, R, C, \mathcal{E} S$ components), efficiency, and continuing motivation. The motivationally adaptive CAI showed higher effectiveness, overall motivation, and attention than the other two CAI types. For efficiency, both motivationally adaptive $C A I$ and motivationally minimized CAI were higher than motivationally saturated CAI. For continuing motivation, there were no significant differences among the three CAI types, but a significant correlation was found between overall motivation and continuing motivation across the three CAI types. This study supports the conclusion that CAI can be designed to be motivationally adaptive to respond to changes in learner motivation that may occur over time. It also illustrates that the ARCS model can be useful and effective in support of designing for these dynamic aspects of motivation.
Computer-mediated instruction (CMI) is being used ever more widely as an independent delivery system or to augment classroom and Web-based learning environments. Learners in both the school and the workplace will most likely have increasingly greater amounts of exposure to forms of CMI. However, despite the convenience and potential effectiveness of CMI, there continue to be problems with learner motivation. Initially a new technology is appealing to many people because of its novelty and the variety of features that add interest. However, as computers are becoming more widely used for instructional delivery, the motivation that results from their novelty effects tends to disappear (Keller, 1997; Keller \& Suzuki, 1988). With experience, students will no longer be as excited by these novel features, and it then will become more of a challenge to stimulate and sustain their motivation during computer-mediated instruction.

One approach to making CMI more responsive to individual student needs is by means of adaptive instruction. However, several researchers in the area of adaptive computer-assisted instruction (CAI) have raised concerns about how to include adaptive responses to student motivation. They have pointed out that few previous efforts to design adaptive CAI have considered learner motivation (del Soldato \& du Boulay, 1995; Hativa \& Lesgold, 1991; McCombs, Eschenbrenner, \& O'Neill, 1973). Their main concern has been that although possible benefits of developing adaptive CAI have been found, one limitation of prior adaptive instruction (e.g., Atkinson, 1976; Holland, 1977; Houlihan, Finkelstein, \& Johnson, 1992; Mills \& 
Ragan, 1994; Ross \& Morrison, 1988; Tennyson \& Christensen, 1988; Tennyson \& Park, 1980) is that student motivation to learn is disregarded or assumed to be embedded in the cognitively adaptive CAI. They have proposed the development of motivationally adaptive CAI that is adjusted to motivational changes for better learning outcomes. However, because none of the current approaches to CAI deals adequately with this problem, the present study was conducted to develop and test an approach to motivationally adaptive CAI based on a validated approach to motivational design.

Current approaches to the design and development of motivating CAI can be divided into three categories. The first is the computer-feature approach, in which specific computer features and novelty effects (Clark, 1983) are assumed to increase the appeal of CAI. For example, Brown pointed out, "the student is rewarded by the use of the machine itself" (Brown, 1986, p. 28). Also, it has been contended that "the cumulative effects of entities such as color, graphics, and animation can be instructionally and motivationally powerful" (Relan, 1992, p. 619). The second category is the principle-seeking approach, in which prescriptive motivational design principles and tactics for CAI are identified or developed from diverse theoretical and practical perspectives. For example, instructional games are recommended for the development of motivating CAI (Dempsey, Lucassen, Gilley, \& Rasmussen, 1993; Malone, 1981; Malouf, 1988). Cooperative learning on CAI (Johnson \& Johnson, 1986) is also suggested, as is learner control of CAI (Klein \& Keller, 1990). The third category is the model-establishing approach. The relationships between motivational theories and computer features are identified and incorporated into a practical model for designing motivating CAI. For example, Lee and Boling (1996) proposed the framework of motivational screen design, and Keller and Suzuki (1988) proposed a set of motivational strategies for designing motivating courseware.

Of the three approaches, the model-establishing approach appears to be the most useful in that it provides a systematic and theoretical frame of reference to guide instructional design- ers. It could represent the dynamic nature of motivation and, therefore, help designers consider how learner motivation changes during computer learning. A goal of the present study was to ground it in such an approach. Current approaches to motivational design in the context of CAI are incomplete because they require that all the motivational strategies be identified and presequenced during the design and development phases, and then they cannot be changed during delivery. However, students who are highly motivated before starting a CAI program will not always remain motivated throughout the whole learning process. And conversely, some students who are not motivated at the beginning may become motivated as they proceed through the program. Therefore, it would be highly desirable to enable the CAI package to be responsive to motivational changes in the learner at different times. In the present study, the idea of an adaptive provision of motivational strategies was tested on CAI as a way of providing optimal motivational strategies.

One of the challenges in responding to changes is to know when to delete motivational strategies as well as when to add them. If learners are already motivated, they may find it demotivating to be exposed to unnecessary enhancing motivational tactics (Astleitner \& Keller, 1995; Keller, 1983, 1987 a, b, c). Therefore, a primary goal of motivationally adaptive CAI is to provide optimal motivational strategies to learners, which means that the CAI should provide the most appropriate motivational strategies in terms of purpose, type, and amount. In other words, the computer should add appropriate motivational strategies when the learners are demotivated and remove unnecessary ones when they are highly motivated.

There have been a few pioneering efforts to develop motivationally adaptive CAI (Astleitner \& Keller, 1995; del Soldato \& du Boulay, 1995; Rezabek, 1994). For example, Rezabek discussed the use of intrinsic motivational strategies for the development of a motivationally adaptive instructional system, but did not provide an empirical test. Astleitner and Keller suggested a simulation approach for designing motivationally adaptive CAI in which they mainly provided ideas on how a computer can predict 
motivational states. Del Soldato and du Boulay developed an intelligent tutoring system in which the system presented test items to be solved by learners, and then both instructional strategies and motivational strategies were prescribed based on student performance. However, none of these studies provided an adaptive approach based on an assessment of learners' motivational states that can be embedded in a variety of types of instructional strategies. It would be desirable to conduct a study that investigates the possibility of developing motivationally adaptive CAI for inclusion in instruction that teaches diverse types of content such as verbal information, concepts, and principles (Gagné, 1985). Regarding this need, del Soldato \& du Boulay suggested that "a richer domain representation, including, for example, a wider variety of links between topics, would provide space for further elaboration of motivational tactics" (p. 373).

Another problem with the ideas suggested by Astleitner and Keller (1995) and del Soldato and du Boulay (1995) is that it is somewhat difficult to apply their models to instructional design. This is because their models basically try to replace motivational capabilities of learners rather than responding to the learners' selfreported motivational states. For example, Astleitner and Keller's approach requires instructional designers to obtain parameters, such as incentive value and other motivational constructs, to be used in their simulation. However, motivationally adaptive CAI does not need to be a complex intelligent tutoring system that replaces learner capabilities. It would be desirable to produce a generic, motivationally adaptive CAI that can be designed in a simpler and more generalizable way.

Finally, it would be desirable to have a theoretical basis for the motivationally adaptive approach that is based on an aggregation of relevant motivational concepts and theories, lends itself to integration with instructional design, and has been validated for effectiveness. In fact, one possible reason that there has not been more effort made to design a motivationally adaptive CAI may have been the lack of a practical model to guide the diagnosis and prescription of learner motivational states (Astleitner \& Keller,
1995). Although McCombs, Eschenbrenner, and $\mathrm{O}^{\prime}$ Neil drew attention to the need for designing motivationally adaptive CAI in 1973, it was not until recently that actual efforts were made to develop such a system.

There have been many motivational theories and models in educational psychology. For example, behavioral theories explain motivation in terms of deprivation and reinforcement. The cognitive view emphasizes attributional theories and intrinsic motivation arising from disequilibrium. The humanistic perspective focuses on growth motivation or need gratification (see Pintrich \& Schunk, 1996, or any other basic text on motivation for detailed explanation of these and other approaches.) However, although these perspectives may help instructional designers understand motivation in diverse ways, they do not provide systematic guidelines for instructional design.

Considering the above situation, the ARCS model is useful for instructional designers because it has the following features:

- It helps one understand the construct of motivation in terms of four distinct categories,

- It provides the systematic motivational design process, and

- It provides motivational strategies.

That is, the ARCS model combines a descriptive synthesis of concepts and theories of motivation with a systematic approach to motivational design. It also provides motivational strategies and tactics.

Historically, there have been other motivational design models. However, the early models tended to focus on one specific motivational characteristic. One of the most prominent of these is Alschuler's approach to developing the achievement motive in children. He developed a six-step process (Alschuler, 1973; Alschuler, Tabor, \& McIntyre, 1971), which was validated and is still effective when applied appropriately. The six-step process is used to arouse the achievement motive in learners and then guide them through a process of internalization.

However, all of the applications of this type of motivational design model fall under the general concept of psychological education. Their purpose is to change the personality and behav- 
ior of students with respect to a specific motivational characteristic rather than focusing more holistically on the design of motivating learning environments.

In educational technology, there are two well-published holistic models of motivational design: (a) the time-continuum model of Wlodkowski (1999), and (b) Keller's ARCS model $(1987 a, b, c)$. The approach taken in this study is based on the ARCS model. The acronym $A R C S$ is derived from four categories of motivational factors (attention, relevance, confidence, and satisfaction) that are based on an aggregation of motivational concepts and theories according to their shared and discriminative attributes. The ARCS model is grounded in a general macrotheory of motivation and performance (Keller, 1979, 1983, 1999) and has been validated in numerous studies and discussions (for example, Bickford, 1989; Keller, 1984; Klein \& Freitag, 1992; Means, Jonassen, \& Dwyer, 1997; Newby, 1991; Nwagbara, 1993; Small \& Gluck, 1994; Visser \& Keller, 1990).

Wlodkowski's (1999) model provides a list of categories of motivational strategies and prescribes when to use them-at the beginning, during, or end of an episode of instruction. This model is prescriptive in that it specifies which types of strategies to use at prespecified time intervals in the instructional process.

The ARCS model is similar to Wlodkowski's approach, but differs from it in two important ways. (a) Strategy selection in the ARCS model is done systematically from a set of categories and subcategories based on a comprehensive synthesis of concepts and theories in human motivation. (b) The ARCS model is a problemsolving approach. Selection of strategies is based on a systematic design process that includes an analysis of audience motivation. Strategies, both the number and type, are then chosen that are appropriate for the given audience.

This problem-solving approach of the ARCS model fits well into developing motivationally adaptive CAI where learner analysis is a key challenge. The categories of the ARCS model provide a basis for making CAI motivationally adaptive by embedding motivational assessments at intervals in the lesson and then having the computer automatically include the most appropriate motivational strategies in response to each assessment.

In this study, a prototype of motivationally adaptive CAI was developed which has the following features:

- It contains a motivational analysis that was done frequently for attention, relevance, and confidence. In a comprehensive approach to adaptive design, one would take measures on all four ARCS categories, and perhaps even some of the subcategories (Keller, 1987c), especially in a long and comprehensive program of instruction. However, in shorter programs, attention, relevance, and confidence are most important because they are the factors that establish one's motivation to learn, and measures of them can easily be used for formative feedback. Measures of satisfaction would normally be taken after the learners had finished a given block of instruction; hence they would be taken less frequently and would be more summative in nature unless the program were long enough to change the incentive structures and other satisfaction elements. In the present study an outcome measure of satisfaction was taken along with the other ARCS dimensions, but only attention, relevance, and confidence were included in the diagnostic and adaptive part of the tutorial. It would be expected that if a successful prototype were established, the process could be applied to longer programs and include satisfaction with the other three categories.

- The assessment method to be used for the embedded audience analysis was another concern. Although Keller (1987b) contended that the full range of measurement possibilities ranging from self-assessment to performance observation and even electronic measures of physiological characteristics can be considered in audience analysis, the case of CAI more or less limits one to self-assessment for practical reasons. In this study, the computer presented three questions at specific internals in the program. The questions asked learners to report their motivation with respect to attention, relevance, and confidence. The researchers judged that that would be the most direct method and the eas- 
iest to use for most instructional designers. However, as a way of partially compensating for the weakness of self-report measures, measures of performance scores on a quiz were also used in conjunction with the motivational self-assessment of confidence.

- A distinction was drawn between enhancement and sustaining tactics even though it was difficult to make. If learners are already motivated when beginning their study, they may find it demotivating to be exposed to unnecessary enhancement motivational tactics (Astleitner \& Keller, 1995; Keller, 1983, 1987 a, b, c). For example, learners who are intrinsically motivated by a given topic may find a tactic such as an unrelated "motivational" game used as an extrinsic reinforcer (as in Lepper, 1985) to be an annoying waste of time. In these cases, just sustaining their motivation, not enhancing it, is recommended. In contrast, in a lesson filled with drill and practice exercises during a long day at school, the opportunity to play such a game could both be satisfying and help overcome boredom. Because it can be difficult to know where to draw the line between the two categories of strategies, the learner motivational analysis is critical. It helps the designer determine where enhancement strategies are required to close motivational gaps, and where there is simply the challenge of sustaining learner interest and confidence.

The purpose of this study was to test the effectiveness, efficiency, and appeal of motivationally adaptive CAI that is based on self-report assessments of motivation with computer-managed motivational strategies drawn from three key areas (attention, relevance, and confidence) of motivation as described by the ARCS model (Keller, 1987a). It was also expected that the motivationally adaptive treatment would result in higher levels of selfreported interest in studying this topic in the future. This is in keeping with Maehr's (1976) concept of continuing motivation, although it uses self-report measures rather than observations of future choices.

To achieve this purpose, a prototype motivationally adaptive CAI was developed and compared to two different motivationally prestructured versions of CAI. The first prestructured version (motivationally saturated CAI) was enhanced with a full set of both enhancement and sustaining motivational strategies. In other words, the goal was to include a large number of motivational tactics, as sometimes happens when instructors or CAI designers incorporate many tactics without regard to the actual motivational levels of the learners. Some researchers (for example, Farmer, 1989), found this to happen when the designers did not conduct a proper audience analysis. It was assumed in the present study that an excessive number of tactics could annoy and demotivate learners. The second prestructured version (motivationally minimized CAI) contained a minimal number of tactics as required to maintain good instructional design, but presumably not enough to improve low motivation.

It was expected that motivationally adaptive CAI would be most motivating to learners because it was designed to: (a) avoid providing excessive motivational strategies that would distract or annoy learners who already found the instruction to be motivating, and (b) overcome motivational deficiencies among learners who were bored or otherwise demotivated by the content. It was also expected that the motivationally adaptive CAI would be most effective in terms of learning achievement and successful in producing the highest perceptions of continuing motivation. Finally, the efficiency of the three versions of CAI was determined by comparing achievement to time spent on the lesson. It was expected that the motivationally adaptive version would be most efficient.

\section{METHOD}

\section{Participants and Design}

Participants were 60 tenth-grade students from the Developmental Research School (DRS) affiliated with a large university in Florida. These students were from three classes, two average and one honors, taught by the same biology teacher. Originally, 66 students were selected from the approximately 85 students in these classes. Some were ineligible because they did 
not return parental approval forms or had some familiarity with the content or software. Six students had to be eliminated from the final analysis when, because of absences, their MAT 7 science scores were not available. Also, out of the 60 students, only 59 were included in the analysis for efficiency; one student scrambled the program so that his data were lost.

Students are selected from the Leon County School District and admitted to the DRS to be representative of Florida's school-age population in terms of academic ability, race, sex, and socio-economic status. The students in the classes in this study represented the overall diversity in the school, except that there were no participants from the lowest academic group or from groups with special needs. The 22 original participants in each of the three classes were randomly assigned to the three levels of CAI (motivationally adaptive, motivationally saturated, and motivationally minimized). This random assignment was expected to help control for potential differences in the participants' entry level knowledge of genetics. The biology teacher provided another control by confirming that these students had not previously learned the content of genetics. The dependent variables were effectiveness (learning), efficiency (amount of learning per time spent), motivation (both overall motivation and each of attention, relevance, confidence, and satisfaction), and perception of continuing motivation.

\section{Materials}

Three versions of HyperCard CAI were developed, containing identical contents on genetics. The contents were adopted and modified from three sources: (a) a print-based biology instructional module developed by Osman (1992), (b) a hypertext CAI developed by Park (1993), and (c) a textbook entitled Biology (Goodman et al., 1989). Genetics was chosen for three reasons. First, the instruction should have a range of content types such as facts, concepts, and principles. This material, as developed by Osman and Park, was systematically designed and validated (Dick \& Carey, 1996) and included those content types. Second, the reading ability level was appropriate to tenth grade students (Park, 1993). Third, it was desirable that the content be somewhat technical and not be easily understood without student effort. If the content were too easy, it could be difficult to determine the effects of motivational treatments and differences in learning. It was confirmed by Park's study and by teachers in the current situation that the material had content validity and could be expected to be sufficiently challenging.

Each of the three versions of CAI (motivationally saturated, adaptive, or minimized) was divided into three sections. At the beginning of each section, the computer asked the students three questions about their motivational attitudes. The first survey was presented at the beginning of the lesson to determine the students' initial attitudes toward the subject. In each survey, they were asked about their level of interest in the content ("I find the subject of genetics interesting: Yes or No"), their perception of its usefulness ("Learning genetics will be useful to me: Yes or $\mathrm{No}^{\prime \prime}$ ), and their confidence in learning it ("I feel confident that I can learn genetics: Yes or $\mathrm{No}^{\prime \prime}$ ).

Immediately following the motivational analysis, they began studying their assigned version and section of the instructional material, which was followed by a quiz covering that section of content. At the end of the instruction, they were asked the continuing motivation question, given the posttest, and given the simplified Instructional Material Motivation Survey (IMMS). Following is the sequence of events in each of the three versions of CAI:

- Introduction and first embedded motivational analysis

- First section of instruction and four-item quiz

- Second embedded motivational analysis

- Second section of instruction and four-item quiz

- Third embedded motivational analysis

- Third section of instruction

- Continuing motivation survey

- Posttest and simplified IMMS 


\section{Treatments}

The motivational strategies used in this study were classified into the two categories of (a) sustaining (Table 1) and (b) enhancing (Table 2) strategies. Keller (1983, 1987 a, b, c) distinguished "enhancing motivation" from "sustaining motivation." He says that strategies for motivational enhancement are provided to learners who require motivational improvements, while strategies for sustaining motivation are provided, as a kind of hygiene factor, to avoid having learners who show the desired levels of motivation become demotivated.

In the case of attention, Strategy AES2 (Table 2 ), "engage the learner's interest by using question-response-feedback interaction that requires active thinking," and Strategy AES3, "present problem-solving situation in a context of exploration and partial revelations of knowledge," were categorized as enhancing strategies to use with learners whose motivation was lower than desirable. As an example of AES2 during the explanation of chromosomes and genes, a question ("Now, do you understand why the baby has black hair?") was asked requiring learners to think about the related concept. And then, an explanation was provided. Also, as an example of AES3 when describing a picture of pea plants, each part name was introduced, one by one, triggering learners' curiosity. However, Strategy ASS1 (Table 1), "keep instructional segments relatively short with progressive disclosure," was categorized as an attention-sustaining strategy. For example, when introducing Mendel's life, the text was presented sequentially in three small paragraphs instead of all at once in a large paragraph.

For the motivationally minimized version, any motivational tactics embedded in Osman's (1992) text, Park's (1993) CAI, and the textbook were eliminated except for certain sustaining tactics. For example, instructional tactics (such as the inclusion of technical drawings in Figure 1) that were judged by instructional design experts as necessary for instructional effectiveness were kept to maintain the inherent quality of the instruction even if they might contribute to positive motivation. This was to ensure that the developed CAI would have minimal motivating features for the students but still be instructionally effective. The motivationally minimized CAI included 3,017 expository words and 210 sentences with several inserted technical drawings. The Hypercard stack size was $112 \mathrm{k}$, and it contained 59 cards. This version of the lesson began with a title screen, an overview of content, the motivational quiz, and an

\section{Table $1 \square$ Motivation sustaining strategies.}

Attention Sustaining Strategies (ASS)

ASS1 Keep instructional segments relatively short with progressive disclosure.

ASS2 Make effective use of screen display to facilitate ease of reading.

ASS3 Intermingle information presentation screens with interactive screens.

ASS4 Use a consistent screen format but with occasional variation.

ASS5 Use visual enhancement functionally to support the instruction and general theme of the lesson.

ASS6 Avoid dysfunctional attention-getting effects such as a flashing word that distracts learner's concentration.

ASS7 Use underlines, italics, or bigger font sizes for the headings or key words.

Relevance Sustaining Strategies (RSS)

RSS1 Use personal pronouns and the learners' name when appropriate.

RSS2 Use graphic illustrations to embed abstract or unfamiliar concepts in a familiar setting.

Confidence Sustaining Strategies (CSS)

CSS1 Allow the learner to escape and return to the menu at any time, and if feasible, to page backwards.

CSS2 Give the learner control over pacing by hitting a key to go from one screen to the next.

CSS3 Match learning requirements to prerequisite knowledge and skills to prevent excessive challenge or boredom. 
Table $2 \square$ Motivation enhancing strategies.

\begin{tabular}{|c|c|c|c|c|}
\hline \multirow{2}{*}{ Strategie } & & \multicolumn{3}{|c|}{ Approximate frequency of use } \\
\hline & & Section 1 & Section 2 & Section 3 \\
\hline \multicolumn{5}{|c|}{ Attention Enhancing Strategies (AES) } \\
\hline AES1 & $\begin{array}{l}\text { Use inverse and flash in text and patterns in pictures } \\
\text { as attention getters. }\end{array}$ & 7 & 4 & 2 \\
\hline AES2 & $\begin{array}{l}\text { Engage the learner's interest by using question- } \\
\text { response-feedback interaction that requires } \\
\text { active thinking. }\end{array}$ & 3 & 2 & \\
\hline AES3 & $\begin{array}{l}\text { Present problem-solving situation in a context of } \\
\text { exploration and partial revelations of knowledge. }\end{array}$ & 5 & 3 & 1 \\
\hline \multicolumn{5}{|c|}{ Relevance Enhancing Strategies (RES) } \\
\hline RES1 & $\begin{array}{l}\text { Use examples from content areas and situation that } \\
\text { are familiar to the learners }\end{array}$ & 2 & & \\
\hline RES2 & $\begin{array}{l}\text { Clearly state the objectives in terms of the } \\
\text { importance or utility of the lesson }\end{array}$ & 2 & 3 & 1 \\
\hline \multicolumn{5}{|c|}{ Confidence Enhancing Strategies (CES) } \\
\hline CES1 & $\begin{array}{l}\text { Use words and phrases that help attribute success } \\
\text { to the learners' effort and ability. }\end{array}$ & 1 & 1 & 1 \\
\hline CES2 & $\begin{array}{l}\text { Clearly present the objectives and the overall } \\
\text { structure of the lesson. }\end{array}$ & 4 & 1 & \\
\hline CES3 & $\begin{array}{l}\text { Explain the evaluative criteria and provide } \\
\text { opportunities for practice with feedback. }\end{array}$ & & & 2 \\
\hline CES4 & $\begin{array}{l}\text { Mention the prerequisite knowledge, skills, or } \\
\text { attitudes that will help the learner succeed at } \\
\text { the task. }\end{array}$ & 1 & 1 & 1 \\
\hline CES5 & $\begin{array}{l}\text { Tell the learner how many items are going to be } \\
\text { in a test or drill and whether it will be timed. }\end{array}$ & 1 & 1 & 1 \\
\hline CES6 & Provide summary. & 2 & 3 & 1 \\
\hline CES7 & $\begin{array}{l}\text { Use a menu-driven structure to provide learner } \\
\text { control over access to different part of } \\
\text { the courseware. }\end{array}$ & 1 & 1 & 1 \\
\hline
\end{tabular}

introduction. Screens were kept uncluttered with parsimonious text (for example, as in Figure 1) and illustrations were used where appropriate to support learning.

The motivationally minimized CAI was not expected to be highly motivating to students except in two possible situations: (a) when the content was intrinsically motivating to them, or (b) when the computer itself might have motivating effects. However, these two situations were not expected to affect many of the learners because of the technical nature of the content. It was also expected that there would be a minimal novelty effect of using the computer because of the previous computer-usage experiences of learners as confirmed by their teachers. In any case, any effects of these types were expected to be randomly distributed across treatments.

Motivationally saturated CAI was developed from the motivationally minimized version. Tactic selection was based on the application of the ARCS model design process, motivational tactics presented by Keller and Suzuki (1988), tactics obtained from interviews with two biology teachers, and other tactics proven in previous studies (e.g., Bickford, 1989; Keller \& Burkman, 1993) to be motivating under appropriate circumstances. These resources provided a pool from which 24 were chosen that fulfilled the results of audience analysis and met the following criteria established by Keller (1987b):

- Not take up too much instructional time,

- Not detract from the instructional objectives,

- Fall within the time and money constraints of 
Figure $1 \square$ Example of motivationally minimized screen.

As an individual formed by a sperm cell and an egg cell grows into an adult, the genes influence its development. The genes cause it to resemble the parents who supplied the chromosomes. For example, the reason a baby has black hair is that its parents transferred genes for black hair to the baby through chromosomes.

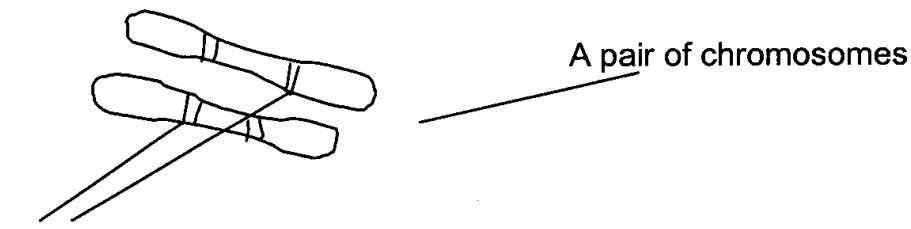

genes

NEXT

the development and implementation aspects of the instruction,

- Be acceptable to the audience,

- Be compatible with the delivery system,

- Be appropriate for the contents, and

- Not bother multiple learners in the classroom.

Because the motivationally saturated CAI incorporated all the motivational strategies (both enhancing and sustaining strategies) for all three components (attention, relevance, and confidence), it might seem that the motivationally saturated CAI would maximize learner motivation. However, research based on application of the ARCS model (e.g., Farmer, 1989; Visser \& Keller, 1990) did not support the excessive use of motivational strategies because it can actually decrease motivation by annoying the learner, which is the reason for including this level of the independent variable. The motivationally saturated CAI contained 3,306 expository words and 273 sentences. It also included additional words $(1,835)$ and sentences (247) for motivational strategies, with technical drawings and tables inserted. The stack size was 393k, and it contained 107 cards.
In the saturated version, screens were either added or modified in many instances to promote motivational features without adding new content. For example, the screen in Figure 1 is the 7 th screen in the minimized program, but it is the 12 th in the saturated version. The additions included a personal orientation screen, two screens designed to enhance motivation, and two "builds," which presented the material in Figure 1 as a progressive disclosure. The content of this screen was introduced as a problem by asking the learner a question and then presenting the answer in a later screen. Figure 2 illustrates a screen designed to stimulate curiosity and relevance.

With motivationally adaptive CAI, a student could encounter up to 8 motivational scenarios (combinations of motivational strategies) in the first section of instruction, and up to 16 motivational enhancement scenarios in the second and third sections. Prior to beginning the first section, the student responded to the three-item embedded motivational survey. There were six possible combinations representing responses of high or low to each of the three motivational conditions (attention, relevance, and confidence). Hence, there were three factors with two 
Figure $2 \square$ Sample screen with curiosity and relevance tactics.

Think about the questions below for a moment before reading further. The answers will be in the reading material.

What do you think genetics is for?

How do you think hair color, eye color, and facial structure are transferred from parents to offspring?

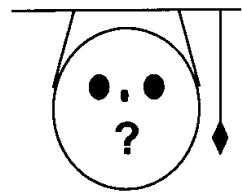

Mom's black Hair

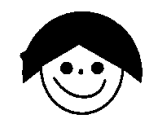

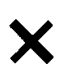

Baby's black hair

PREVIOUS

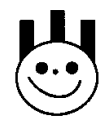

Dad's black hair .
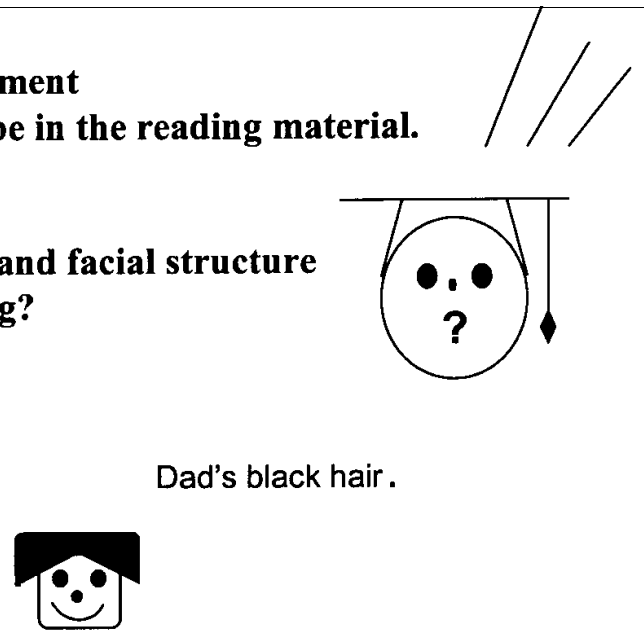
tively. Items were eliminated from selection that did not reflect the motivational features of the programs used. For example, the original item "The exercises in this lesson were too difficult." was eliminated because the CAI programs did not have exercises. Students were asked to respond on a five-point survey with response choices of 1 (not true), 2 (slightly true), 3 (moderately true), 4 (mostly true), and 5 (very true). The potential total range score was from 16 to 80 . Sample items were, "The materials are eyecatching" (A); "Completing this lesson successfully was important to me" (R); "I could understand most of this lesson" (C); and "I really liked studying this lesson" (S). The reliability coefficient obtained by Cronbach's Alpha for the overall motivation measure was .92, and it was $.79, .73, .70$, and .85 for attention, relevance, confidence, and satisfaction, respectively.

Effectiveness. Learning achievement (effectiveness) was measured by a 13 -item posttest covering the following objectives: Students will be able to:

- Choose correct features of pea plants that enabled Mendel to succeed in discovering the principles of heredity.

- Select correct descriptions of Mendel's three principles of heredity.

- Choose correct examples of concepts used in the study of heredity.

- Solve heredity problems using Mendel's three principles.

The 13 multiple-choice items were adopted or revised from a test with 24 items used in a prior study (Park, 1993) so that students could complete all the requirements within the experimental time available for the study. Park reported the reliability of the test as .78 , using the Kuder-Richardson formula (K-R 20). Items were selected based on a table of specifications for the content of instruction; redundant items were excluded from selection. If necessary, revisions were made to clarify the meaning of the questions. Two subject matter experts (biology teachers) validated the test according to the learning objectives using a table of specifications for the content of instruction. Internal consistency of the test using the K-R 20 formula was
.69. The reduction in reliability compared to Park's result could be due to the reduced length of the posttest or the item selection.

Continuing motivation. Self-perception of continuing motivation (Maehr, 1976) was measured by asking students if they wanted to learn more in the future on the same or similar content. Students were told to report their continuing motivation on a Likert-type item with five anchors (1 = strongly disagree, $2=$ disagree, $3=$ not sure, $4=$ agree, 5 = strongly agree). One item stated, "The lesson was motivating to me. I would like to learn more about the same subject matter later."

Efficiency. Efficiency was obtained by multiplying 1,000 to the ratio of performance on the posttest to study time. The computer tracked the time (measured in seconds) used by each student. For instance, if a student scored 8 using 2,000 seconds, 8 was divided by 2,000 , and then multiplied by 1,000 to yield an efficiency of 4 .

\section{Procedure}

One month before the implementation of the treatments, the students were measured on their premotivation to learn genetics. This was done to conduct audience motivational analysis as recommended by the ARCS Model. The oneway analysis of variance (ANOVA) revealed no significant difference among treatments for their motivation to learn genetics, $F(2,57)=.40, M S E$ $=13.60, p=.671$. Also, a significant difference was not found among groups on scores for attention $(F(2,57)=.38, M S E=1.90, p=.683)$, relevance $(F(2,57)=.47, M S E=1.61, p=.630)$, confidence $(F(2,57)=.67, M S E=1.84, p=.515)$, and satisfaction $(F(2,57)=.10, M S E=.30, p=.909)$.

The experiment was conducted for three days at a learning resource center (LRC) in a university building near the students' school. Each day, students from one of the three participating classes reported to the LRC. On the first day, the 22 students from the first class were randomly assigned to the three treatments and completed all of the materials. On the second and third days, 22 students each from the other two participating classes completed the same process. 
Their biology teacher told all learners that they would participate in an experiment, but the teacher did not mention any credit for their participation. We wanted to observe how each treatment would enhance their motivation in the absence of a strong extrinsic incentive. Therefore, although the topic of genetics was part of their regular curriculum, the teacher did not try to force their desire to learn the contents. We recommended that he not emphasize the importance of participation. He simply arranged for the students to participate in the experiment.

The experimenter (the first author) instructed the participants to study the materials, emphasizing that a posttest and survey would be given afterward. The computer assignment and explanation took about 10 to 15 minutes. Then, learners were allowed to study as long as they wanted and the computer recorded their use of time. They were also told to raise a hand when they were ready for the test. The average time used by students was 30.49 min (range $=14.6-$ $46.5 \mathrm{~min}$ ). When students finished the lesson, their self-reported continuing motivation was measured on the computer, which was followed by both the posttest and the simplified IMMS.

\section{Data Analysis}

To test for differences in motivation and continuing motivation among learners in the three versions of CAI, one-way ANOVA was used. To test for differences in attention, relevance, confidence, and satisfaction, multivariate analysis of variance (MANOVA) was conducted. This analysis was followed-up by appropriate univariate analyses. To test for differences in effectiveness (learning achievement) and efficiency, one-way analysis of covariance (ANCOVA) was used with students' science scores on Metropolitan Achievement Test 7 as a covariate. ANCOVA was conducted to control for the potential effect of prior achievement in science. Both ANOVA and ANCOVA were followed by Fisher's least significant difference (LSD) pairwise comparison procedure if a significant difference was found among treatments. Alpha was set at .05 for all statistical tests. All these analyses were done with the Statistical Package for the Social Science (SPSS Windows V. 6.1).

\section{RESULTS}

Because of the attrition of six participants (see Participants and Design) there were 19 students each in the minimized and saturated versions of the CAI, and 22 in the adaptive version. The means and standard deviations for all dependent variables and conditions are presented in Table 3. Possible ranges for each variable are listed in the footnotes to the table.

\section{Motivation}

The one-way ANOVA conducted on overall motivation scores revealed a significant difference for the treatments, $F(2,57)=4.46, M S E=$ $630.44, p<.05$. Approximately $14 \%$ of the difference in motivation was explained by the treatments. Observed power was .74. Fisher's LSD pairwise comparison procedures revealed that students in the motivationally adaptive CAI ( $M$ $=52.73, S D=12.09)$ showed higher motivation than those in both motivationally saturated $(M=$ $43.63, S D=9.38)$ and motivationally minimized CAI $(M=42.84, S D=13.75)$. The mean for the motivationally adaptive CAI was at the 57th percentile of the range between 16 and 80 , whereas those for the motivationally saturated and minimized versions were at the 43rd and 42nd percentiles, respectively.

\section{Attention, Relevance, Confidence, Satisfaction}

MANOVA indicated that the CAI treatments had an effect on components of motivation, Wilks's Lambda $=.711, F(8,108)=2.514, p<.05$. Univariate analyses indicated that differences occurred only for attention and relevance. For attention, there was a significant difference for the treatments, $F(2,57)=5.07, M S E=62.45, p<$ .01. Approximately $15 \%$ of the difference in attention was explained by the treatment, and observed power was .80. Fisher's LSD pairwise comparison procedures revealed that students in the motivationally adaptive CAI $(M=13.36$, $S D=3.36)$ showed higher attention than those in both motivationally saturated $(M=10.95, S D=$ 3.19) and motivationally minimized CAI ( $M=$ $10.00, S D=3.96)$. The mean for the motivation- 
respectively. There was not a significant difference for confidence and satisfaction.

\section{Effectiveness}

Because the correlation coefficient between science scores (covariate) and posttest scores was significantly high $(r=.54, p=.001)$, one-way ANCOVA was conducted on achievement scores. The results showed a significant difference for the treatments, $F(2,56)=5.28, M S E=$ $29.58, p<.01$. Approximately $16 \%$ of the difference in achievement was explained by the treatments. Observed power was .82. Fisher's LSD pairwise comparison procedures revealed that students in the motivationally adaptive CAI (observed $M=7.18, S D=2.50$ ) performed significantly better than those in both motivationally saturated (observed $M=5.84, S D=3.11$ ) and motivationally minimized CAI (observed $\mathrm{M}=6.68, \mathrm{SD}=3.35$ ). The overall achievement of the groups varied around the 50th percentile because of the difficulty level of the test. This was deliberate in order to create a greater range of possible effects of the motivational tactics.

To investigate the validity of the rationale for the assumption that increased motivation will produce more effectiveness, the correlation between overall motivation and adjusted posttest scores was calculated (there was no significant correlation between motivation and nonadjusted posttest scores). The observed posttest scores were transformed into adjusted scores for the covariate on the validated assumption of homogeneity of regression coefficient. The Pearson product-moment correlation $r$ was $.2546(p<.05)$. This implies that about $6.5 \%$ of the achievement variance can be explained by the differences in overall motivation when the confounding effects of the covariate are systematically removed. This explained variance is larger than the $2.5 \%$ that was reported by Bickford (1989), who used the ARCS model for printed material instruction nonadaptively.

\section{Continuing Motivation}

Although the students in the motivationally adaptive CAI $(M=3.18, S D=1.10)$ showed higher self-reported continuing motivation than both the motivationally saturated $(M=2.42, S D$ $=1.07)$ and motivationally minimized CAI $(M=$ $2.63, S D=.96)$, the one-way ANOVA did not reveal a significant difference for the treatments, $F(2,57)=2.93, M S E=3.20, p=.061$. Approximately $9 \%$ of the difference in continuing motivation was explained by the treatment. Observed power was .549.

\section{Efficiency}

As with effectiveness, the correlation coefficient between science scores and the efficiency measure was significant $(r=.4728, p=.001)$. Oneway ANCOVA revealed a significant difference for treatments, $F(2,55)=5.17, M S E=15.03, p<$ .01 . Approximately $16 \%$ of the difference in efficiency was explained by the treatment, and observed power was .81. Fisher's LSD pairwise comparison procedures revealed that students in both the motivationally adaptive CAI (observed $M=4.01, S D=1.65$ ) and motivationally minimized CAI (observed $M=4.62, S D=$ 2.25) showed higher efficiency than those in the motivationally saturated CAI (observed $M=$ $3.11, S D=2.11$ ).

\section{DISCUSSION}

The purpose of this study was to investigate the effects of a motivationally adaptive CAI developed in accordance with systematic motivational design principles as represented in the ARCS model (Keller, 1987a, b, 1999). For this purpose, a prototype of motivationally adaptive CAI was developed and compared to motivationally saturated and motivationally minimized versions for its effects on motivation (overall motivation, attention, relevance, confidence, and satisfaction), effectiveness, continuing motivation, and efficiency.

Results indicated that motivationally adaptive CAI was superior to the other two CAI types for the enhancement of overall motivation and attention. Regarding the other subcomponents of motivation, the adaptive use of motivational strategies was partly supported. For relevance, students in the motivationally adaptive CAI showed higher scores than the 
motivationally saturated CAI but not the motivationally minimized version. Regarding confidence and satisfaction, although students in the motivationally adaptive CAI showed the highest scores, significant differences were not found among three CAI types.

These findings may be explained as follows. The fact that students in the motivationally saturated CAI showed the lowest relevance score supports the contention that motivational strategies need to be prescribed optimally; that is, adaptively. In the motivationally saturated CAI, strategies for the three components of attention, relevance, and confidence were provided and distributed throughout the instruction. Therefore, students had to be exposed to much more material than those who received either motivationally adaptive or motivationally minimized CAI. For example, the number of total words used in the motivationally saturated CAI was 5,141 , while the motivationally minimized CAI had only 3,017 words. Of the difference $(2,124), 1,835$ words were used for motivational strategies, and this extra burden of words may have hindered the relevance strategies from influencing students. Or, to put it differently, the large amount of irrelevant content may have depressed their relevance scores.

The fact that there was no significant difference for relevance between the motivationally minimized CAI and the motivationally adaptive CAI was noteworthy. What would have produced the unexpected relevance level in the motivationally minimized CAI? One possible explanation is that student exposure to the content only, without distraction, allowed them to recognize the relevance as they learned more about the content even though they were not given specific relevance strategies. This inference may be supported by the fact that students in the motivationally minimized CAI showed higher achievement than those in the motivationally saturated CAI who were presumed to be distracted by all the motivational strategies. However, the difference in achievement between these two treatments was not significant, so additional research would have to be done to confirm or negate this inference.

Another interesting finding is that there were no differences in confidence among the three conditions. This can be interpreted in two ways. First, it is possible that the prescribed confidence strategies (such as "use words and phrases that help attribute success to the learners' effort and ability," shown in Table 2) were not strong enough to address the motivational needs. In fact, this is a possible inference in that not all of the powerful computer features could be used because of the constraints of experimental conditions. Second, provision of review opportunities could have resulted in nonsignificant differences in confidence among the three conditions. Research results show that review opportunities are effective strategies for increasing student confidence (Bickford,1989). Therefore, review opportunities that were provided before and after each quiz may have contributed to maintaining or enhancing learner confidence regardless of condition. Further investigation of this inference needs to be done in future studies.

Aside from the motivational benefits of the adaptive use of the ARCS model, another expected benefit was to increase achievement scores. Although motivation to learn is not the only predictor of student achievement, it seemed reasonable to predict that if motivationally adaptive CAI is more motivating than the other two CAI types, it would also show the highest effectiveness. The results of this study supported this expectation.

Regarding continuing motivation, which was self-reported in this study, $\operatorname{Keller}(1983,1987 a, b)$ pointed out that the more highly motivated the learners are during their learning, the better chance of their having high continuing motivation after their learning. In the present study, students in the motivationally adaptive CAI showed the highest continuing motivation, but it was not enough to be significantly different from those of students in the other two CAI types. The observed power for ANOVA on continuing motivation was .549; therefore it might be that a larger sample size or longer treatment would result in significant differences among the three conditions. If one considers the relationship between overall motivation and continuing motivation in the three conditions, the correlations were in the right direction. The motivationally adaptive CAI showed the highest correlation $(r=.82, p<.001)$, while the 
motivationally minimized CAI was also significant $(r=.64, p=.003)$. It is interesting that the motivationally saturated CAI showed the lowest correlation, $r=.34$, which was not significant ( $p$ $=.151$ ).

For efficiency, it was expected that learners in the motivationally adaptive CAI would need less time to finish their learning than those who had to go through all the motivational strategies in the motivationally saturated CAI. Also, it was expected that the motivationally minimized CAI would require less time to finish than the other conditions because no motivation enhancement strategies were provided. The analyses of efficiency showed that the motivationally adaptive and motivationally minimized conditions had higher efficiency than the motivationally saturated condition. These findings support the need for providing motivational strategies adaptively for efficiency. The excessive provision of motivational strategies in the motivationally saturated CAI resulted, as expected, in lower efficiency than the motivationally minimized CAI, while the motivationally adaptive CAI showed the same efficiency with the motivationally minimized CAI.

In summary, motivationally adaptive CAI was generally supported by the data in terms of its motivation, effectiveness, overall motivation, and efficiency. The data also indicated that there is a significant correlation between motivation and continuing motivation. These findings support the adaptive provision of motivational strategies in CAI.

\section{Considerations for Future Research}

As an initial attempt to design and develop a motivationally adaptive CAI, this study has limitations to be considered in the design of future studies. First, the potential range of motivational strategies could not be fully actualized because of constraints of available hardware and software. For example, after instruction, many students commented on the lack of color, animation, and sound for more motivational features. Some important conditions (Astleitner \& Keller, 1995) for motivated learners, such as self-created task solution, opportunities for advanced topics, and control over important parts of the learning environment were not used.

Second, the time for the experiment was short. The average time was 30.49 minutes across three conditions (motivationally minimized CAI: 24.37 , saturated CAI: 35.45 , adaptive CAI: 31.21). Considering the limited use of motivational strategies as discussed above, this short-term exposure to motivational strategies could have been another reason for showing several insignificant differences despite the overall positive results that were found.

Third, the use of self-report methods for measuring motivation was limited in that such methods required students to indicate their perceived motivation level, which might have been different from their actual amount of effort-a more accurate measure of motivational behavior. Also, the embedded motivational analyses may have been intrusive, requiring students to stop their process of learning. A more natural way of measuring motivation would be desirable.

Fourth, motivational strategies used in this study may not have been as closely targeted to the real motivational needs of students as would be desirable. The present study used one global question for each of the three major components of motivation. It might be more effective to focus on the subcategories of each component for more reliable diagnosis and prescription. For example, confidence is composed of the subcomponents of motive matching, goal orientation, and familiarity (Keller, 1987a, c). If motivational analysis were done for each of these subcomponents, adaptive CAI might be more effective in enhancing student confidence.

\section{Conclusion}

Despite the limitations in this prototype development study, the results demonstrate that it is feasible to design motivationally adaptive instruction for a self-paced learning setting such as CAI. They also demonstrate that self-reports of motivation can be valid indicators of learning readiness to which motivational strategies are adaptively prescribed. And, the study 
demonstrates that the ARCS model can be applied effectively to the design of motivationally adaptive CAI. Further research should lead to more sophisticated and effective applications of motivationally adaptive design.

Sang H. Song is at Andong National University, Korea.

John M. Keller is at Florida State University.

\section{REFERENCES}

Alschuler, A.S. (1973). Developing achievement motivation in adolescents: Education for human growth. Englewood Cliffs, NJ: Educational Technology Publications.

Alschuler, A.S., Tabor, D., \& McIntyre, J. (1971). Teaching achievement motivation: Theory and practice in psychological education. Middletown, CT: Education Ventures, Inc.

Astleitner, J., \& Keller, J.M. (1995). A model for motivationally adaptive computer-assisted instruction. Journal of Research on Computing in Education, 27(3), 270-280.

Atkinson, R.C. (1976). Adaptive instructional systems: Some attempts to optimize the learning process. In D. Klahr (Ed.), Cognition and instruction (pp. 81-108). New York: Wiley \& Sons.

Bickford, N.L. (1989). The systematic application of principles of motivation to the design of printed instructional materials. Unpublished doctoral dissertation. Florida State University, Florida.

Brown, J. (1986). Some motivational issues in computer-based instruction. Educational Technology, 26(4), 27-29.

Clark, R.E. (1983). Reconsidering research on learning from media. Review of Educational Research, 53(4), 445-459.

del Soldato, T., \& du Boulay, B. (1995). Implementation of motivational tactics in tutoring systems. Journal of Artificial Intelligence in Education, 6(4), 337-378.

Dempsey, J., Lucassen, B., Gilley, W., \& Rasmussen, K. (1993). Since Malone's theory of intrinsically motivating instruction: What's the score in the gaming literature? Journal of Educational Technology Systems, 22(2), 173-184.

Dick, W., \& Carey, L. (1996). The systematic design of instruction (4th ed.). New York: Harper Collins.

Farmer, T.M. (1989). A refinement of the ARCS motivational design procedure using a formative evaluation methodology. Unpublished doctoral dissertation, Indiana University, Indiana.

Gagné, R.M. (1985). The conditions of learning and theory of instruction (4th ed.). New York: Holt, Rinehart \& Winston.

Goodman, H.D., et al. (1989). Biology. Orlando, FL: Harcourt Brace Jovanovich
Hativa, N., \& Lesgold, A. (1991). The computer as a tutor-Can it adapt to the individual learner? Instructional Science, 20(1), 49-78.

Holland, J.G. (1977). Variables in adaptive decisions in individual instruction. Educational Psychologist, 12(2), 146-161.

Houlihan, P.A., Finkelstein, M.W., \& Johnson, L.A. (1992). Adaptive use of the DDx\&Tx system. Journal of Computer-Based Instruction, 19(4), 125-130.

Johnson, D.W., \& Johnson, R.T. (1986). Computerassisted cooperative learning. Educational Technology, 26(1), 12-18.

Keller, J.M. (1979). Motivation and instructional design: A theoretical perspective. Journal of Instructional Development, 2(4), 26-34.

Keller, J.M. (1983). Motivational design of instruction. In C.M. Reigeluth (Ed.), Instructional-design theories and models: An overview of their current status (pp. 386-434). Hillsdale, NJ: Lawrence Erlbaum Associates.

Keller, J.M. (1987a). Strategies for stimulating the motivation to learn. Performance and Instruction Journal, 26(8), 1-7.

Keller, J.M. (1987b). The systematic process of motivational design. Performance and Instruction Journal 26(9/10), 1-8.

Keller, J.M. (1987c). Development and use of the ARCS model of instructional design. Journal of Instructional Development, 10(3), 2-10.

Keller, J.M. (1993). Motivation by design. Unpublished manuscript, Florida State University, Florida.

Keller, J.M. (1997). Motivational design and multimedia: Beyond the novelty effect. Strategic Human Resource Development Review, 1(1), 188-203.

Keller, J.M. (1999). Motivational systems. In $\mathrm{H}$. Stolovitch, \& E. Keeps (Eds.), Handbook of human performance technology (2nd ed.). San Francisco: JosseyBass Inc. Publishers.

Keller, J.M., \& Burkman, E. (1993). Motivation principles. In M. Fleming \& W.H. Levie (Eds.), Instructional message design: Principles from the behavioral and cognitive sciences. Englewood Cliffs, NJ: Educational Technology Press.

Keller, J.M., \& Suzuki, K. (1988). Use of the ARCS motivation model in courseware design. In D.H. Jonassen (Ed.), Instructional designs for microcomputer courseware (pp. 401-434). Hillsdale, NJ: Lawrence Erlbaum Associates.

Klein, J.D., \& Freitag, E.T. (1992). Training students to utilize self-motivational strategies. Educational Technology, 32(3), 44-48.

Klein, J.D., \& Keller, J.M. (1990). Influence of student ability, locus of control, and type of instructional control on performance and confidence. Journal of Educational Research, 83(3), 140-146.

Lee, S.H. \& Boling, E. (1996). Motivational screen design guidelines for effective computer-mediated instruction. Proceedings of Selected Research and Development Presentations at the 1996 National Convention of the Association for Educational Communications and 
Technology, Indianapolis, Indiana, 401-412.

Lepper, M.R. (1985). Microcomputers in education: Motivational and social issues, American Psychologist, 40(1), 1-18.

Maehr, M.L. (1976). Continuing motivation: An analysis of a seldom considered educational outcome. Review of Educational Research, 46(3), 443-462.

Malone, T. (1981). Toward a theory of intrinsically motivation instruction, Cognitive Science, 4, 333-369.

Malouf, D.B. (1988). The effect of instructional computer games on continuing student motivation. The Journal of Special Education, 21(4), 27-38.

McCombs, B.L., Eschenbrenner, A.J., Jr., \& O'Neill, H.F., Jr. (1973). An adaptive model for utilizing learner characteristics in computer based instructional systems. Educational Technology, 13(4), 47-51.

Means, T.B., Jonassen, D.H., \& Dwyer, F.M. (1997). Enhancing relevance: Embedded ARCS strategies vs. purpose. Educational Technology Research and Development, 45(1), 5-18.

Mills, S.C., \& Ragan, T.J. (1994). Adapting instruction to individual learner differences: A research paradigm for computer-based instruction. Proceedings of Selected Research and Development Presentations at the 1994 National Convention of the Association for Educational Communications and Technology, Nashville, Tennessee, 525-546.

Newby, T.J. (1991), Classroom motivation: Strategies of first-year teachers. Journal of Educational Psychology, 83(2), 195-200.

Nwagbara, C.I. (1993). Effects of the relevance component of the ARCS model of motivational design. Unpublished doctoral dissertation. Purdue University, Indiana.

Osman, M. (1992). The effects of think-ahead questions and prior knowledge on learning and retention. Unpublished Doctoral Dissertation, Florida State University, Florida.

Park, I.W. (1993). The effects of orienting questions and prior knowledge on learning in hypertext. Unpublished doctoral dissertation, Florida State University, Florida.
Pintrich. P.R., \& Schunk, D.H. (1996). Motivation in education: Theory, research, and applications. Englewood, Cliffs, NJ: Prentice Hall.

Relan, A. (1992). Motivational strategies in computerbased instruction: Some lessons from theories and models of motivation. Proceedings of Selected Research and Development Presentations at the Convention of the Association for Educational Communications and Technology, 612-624.

Rezabek, R.H. (1994). Utilizing intrinsic motivation in the design of instruction. Proceedings of Selected Research and Development Presentations at the National Convention of the Association for Educational Communications and Technology , Nashville, Indiana, 695-704.

Ross, S.M., \& Morrison, G.R. (1988). Adapting instruction to learner performance and background variables. In D.H. Jonassen (Ed.), Instructional designs for microcomputer courseware (pp. 227-243). Hillsdale, NJ: Lawrence Erlbaum Associates.

Small, R.V., \& Gluck, M. (1994). The relationship of motivational conditions to effective instructional attributes: A magnitude scaling approach. Educational Technology, 34(8), 33-40.

Tennyson, R.D., \& Christensen, D.L. (1988). MAIS: an intelligent learning system. In D. Jonassen, (Ed.), Instructional designs for micro computer courseware (pp. 247-74). Hillsdale, NJ: Lawrence Erlbaum.

Tennyson, R.D., \& Park, S. (1984). Process learning time as an adaptive design variable in concept learning using computer-based instruction. Journal of Educational Psychology, 76, 452-465.

Tuckman, B.W. (1994). Conducting educational research (4th ed.). New York: Harcourt Brace \& Company.

Visser, J., \& Keller, J.M. (1990). The clinical use of motivational messages: An inquiry into the validity of the ARCS model of motivational design. Instructional Science, 19, 467-500.

Wlodkowski, R.J. (1999). Enhancing adult motivation to learn (2nd ed.). San Francisco: Jossey-Bass. 